\title{
A computer-controlled cardiotachometer
}

\author{
WOLFGANG KLOSTERHALFEN \\ University of Düsseldorf, 4000 Düsseldorf, Federal Republic of Germany
}

\begin{abstract}
A versatile display system for presenting heart rate information is described. The display has a table with 10 rows and 50 columns. This 10 by 50 matrix contains all integers from 0 to 499 , so that it can display the instantaneous R-R intervals of a rat's EKG to the nearest millisecond. At each beat 1 of 10 vertically and 1 of 50 horizontally arranged indicator lights are turned on to provide the coordinates for reading the table. Either beat-to-beat or averaged heart rate or period is displayed. Small and large changes can be easily and accurately observed on the same scale. The lights are controlled by a PDP-8/e. A listing of the assembler program is presented.
\end{abstract}

In a large number of psychophysiological investigations involving measurement of heart rate (HR), an immediate indication of ongoing $\mathrm{HR}$ behavior is essential or at least helpful (e.g., studies of biofeedback, stress, habituation, or classical conditioning).

\section{TYPES OF CARDIOTACHOMETERS}

Several different cardiotachometers are available. The design of these units is usually based on analog circuitry that provides a voltage proportional to the reciprocal of the time interval between successive $R$ waves. $\mathrm{HR}$ is indicated by a needle or pen that points to a scale (voltmeter type) or writes "staircases" on recording paper (tachograph) (e.g., Pope, Deboo, \& Smith, 1968). Readings from these instruments are far from being exact.

Digital tachometers are highly accurate (e.g., Elings \& Holly, 1973), but the dynamics of HR changes are poorly represented by numbers, and watching beat-tobeat changes in HR over a longer period of time on a LED display is a tedious job that absorbs most of the experimenter's attention.

Computers have been used successfully for the interpretation of the EKG complex (e.g., Wartak, Milliken, \& Karchmar, 1970), but they have contributed little to improving $\mathrm{HR}$ monitoring. A computer-controlled cardiotachometer (CCC) that is accurate, easily readable, and versatile is described here.

\section{COMPUTER-CONTROLLED CARDIOTACHOMETER}

\section{Display}

The CCC's display has an interchangeable table of HR or heart period values. Ten vertically and 50 hori-

Development of this system was supported in part by Grant Li 74/10 from the Deutsche Forschungsgemeinschaft to Gustav A. Lienert. Requests for reprints should be addressed to Wolfgang Klosterhalfen, Institut fuer Medizinische Psychologie der Universitaet Duesseldorf, Universitaetsstrasse 1, 4000 Duesseldorf, Federal Republic of Germany. zontally arranged indicator lights provide the coordinates for reading this 10 by 50 table (see Figure 1): At each beat one of the vertical and one of the horizontal lights are turned on. The first row of this matrix may, for example, contain R-R intervals from 0 (upper left corner) to $49 \mathrm{msec}$ (upper right corner). For these values the top light of the vertical string and one of the horizontal lights point to the corresponding number in the table. The second verticle light is used for the second row (50 to 99), and so on, so that the lights can indicate any integer from 0 to 499 .

The table shown in Figure 1, which is used for monitoring HR in rats, is based on this scaling. But following a convention, values are expressed in beats per minute (bpm).

\section{Computer}

A PDP-8/e computer with an almost noiseless reed relay interface (special fabrication) and a real-time clock (DK8-ES) was employed to control the CCC. However, almost any microcomputer with real-time clock and (multiplexed) TTL outputs to drive LEDs should be satisfactory (e.g., Brown \& Deffenbacher, 1978). The EKG signal is fed directly or via an R-wave detector circuit (Shimizu, 1978) into the clock's Schmitt trigger input. An assembler program written in PAL8 uses approximately 100 locations (see Appendix). It measures R-R intervals and sets the relays for the lights of the CCC (see Figure 2). The 50 horizontal lights are multiplexed: They are connected to power in groups of 5 by 10 relays of Register 1 , and grounded in groups of 10 by 5 relays of Register 2; 50 diodes (omitted in Figure 2) are connected in series to prevent loops. The 10 vertical lights are turned on by 10 relays of Register 3.

Depending on the position of bit 0 of the switch register, the CCC displays either beat-to-beat or averaged HR.

\section{Applications}

The CCC has operated reliably for several years and 


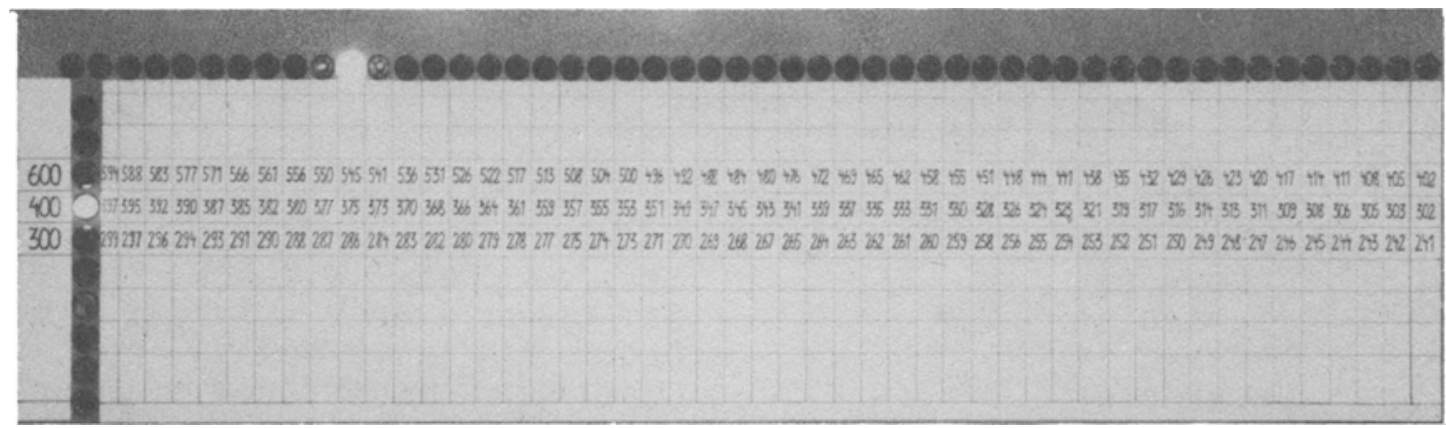

Figure 1. Prototype of a computer-controlled cardiotachometer $(100 \times 30 \times 8 \mathrm{~cm})$ indicating 375 beats per minute.

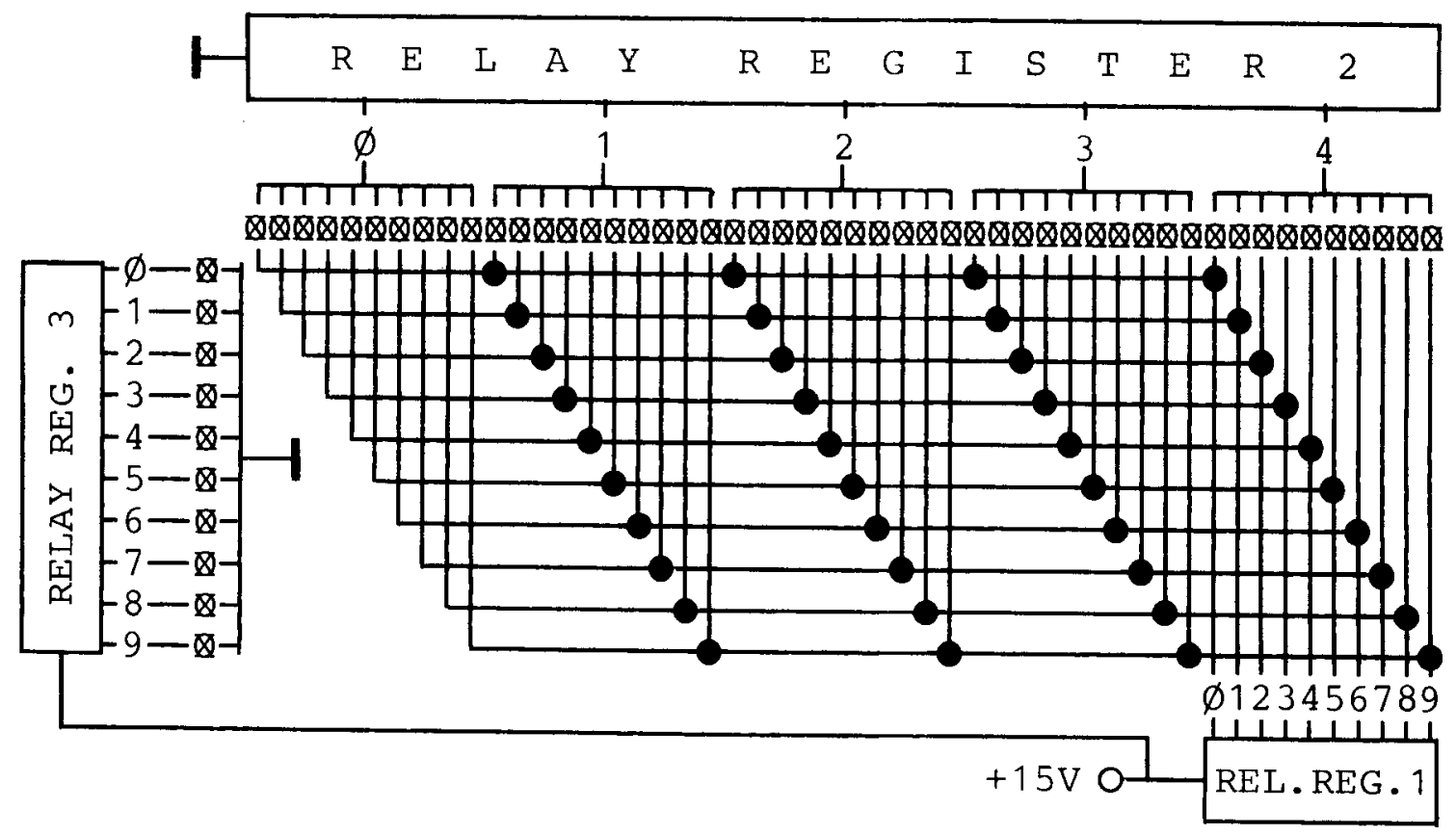

Figure 2. Relay circuits for control of the tachometer's lights.

has proved very helpful in studying the effects of acoustic stimulation on HR in rats. Using the table shown in Figure 1 and an average over four intervals, the lights performed fairly continuous movements rather than jumps. The green, yellow, and red horizontal lights, indicating ranges of $241-300,302.400$, and $402-600$ bpm, respectively, required little attention. As each range is spatially represented by a meter, rather than by a centimeter as in conventional tachographs, good HR readings can be obtained at a glance, even from several meters away.

The program for the $\mathrm{CCC}$ is short and does not require fast serving. It may be easily integrated in to larger EKG programs. The CCC can be adapted easily to meet the experimenter's special needs. Changing its range, the time spacing between lights, or the number of averaged intervals can be done by changing the table and a few instructions in the program.

Principally, any variable changing over time may be displayed. Because of its large range, the instrument is well suited, for example, to monitor skin conductance or resistance levels. In this case, other than the table, only the program's input routine has to be changed to accept data from an A/D converter (e.g., AD8-EA). 


\section{REFERENCES}

Brown, E. L., \& Deffenbacher, K. Microcomputers big and little: Selecting a low-cost laboratory computer network. Behavior Research Methods \& Instrumentation, 1978, 10, 241-245.

Elings, V., \& Holly, D. A cardiotachometer which calculates rate digitally. IEEE Transactions on Biomedical Engineering, November 1973, 468-470.
Pope, J. M., Deboo, A. J., \& Smith, D. B. D. A cardiotachometer with linear indication of beat-to-beat frequency. Psychophysiology, 1968, 4, 486-492.

Shimizu, H. Reliable and precise identification of R-waves in the EKG with a simple peak detector. Psychophysiology, 1978, 15, 499-501.

Wartak, J., Milliken, J. A., \& Karchmar, J. Computer program for pattern recognition of electrocardiograms. Computers and Biomedical Research, 1970, 4, 344-374.

\section{- DEFINITIONS}

CLSK $=6131$

$C L O E=6132$

$C L B A=6136$

LDRI $=6141$

$L D R 2=6143$

LDR $3=6145$
, SKIP ON CLOCK INTERRUPT

, SET CLOCK ENABLE REGISTER PER AC

- CLOCK BUFFER TO AC

- LOAD RELAY REGISTER I WITH AC

/ LOAD RELAY REGISTER 2 WITH AC

- LOAD RELAY REGISTER 3 WITH AC

, ROUTINE TO SET THE CLOCK ENABLE REGISTER:

, ON EACH SCHMITT TRIGGER INPUT THE CLOCK

/ - TRANSFERS THE CLOCK COUNTER CONTENTS TO THE CL. BUfFER

- - Clears the Clock counter

- AND STARTS COUNTING FROM ZERO AT I KHZ

62607260

$0261 \quad 1322$

$0202 \quad 6132$
CLOCK.

CLA
TAD ENABLE
CLOE

- CLEAR aCCUMULATOR

- GET CLOCK CONTROL WORD

/ LOAD IT INTO CLOCK ENABLE REGISTER

1 ROUTINE TO MEASURE THE INTERVAL BETWEEN THE LAST TWO

, SCHMITT TRIGGER INPUTS

$\begin{array}{ll}\text { 9293 } & 6131 \\ 9294 & 5293 \\ 0295 & 6136 \\ 9296 & 3323\end{array}$

\author{
, HAS A SCHMITT TRIGGER FIRED ? \\ NO: CHECK AGAIN \\ I YES: READ AND \\ SAVE CLOCK BUFFER CONTENTS
}

CLAA

DCA RRINT

ROUTINE TO CHOICE BETW. AUERAGED AND BEAT-TO-BEAT DISPLAY
SWITCH, LAS
SMA
I LOAD AC WITH SWITCH REGISTER
JMP INIT
I IS SWITCH O SET ?
, NO: PROUIDE A BEAT-TO-BEAT DISPLAY

- ROUTine to Calculate a moving aUERAGe

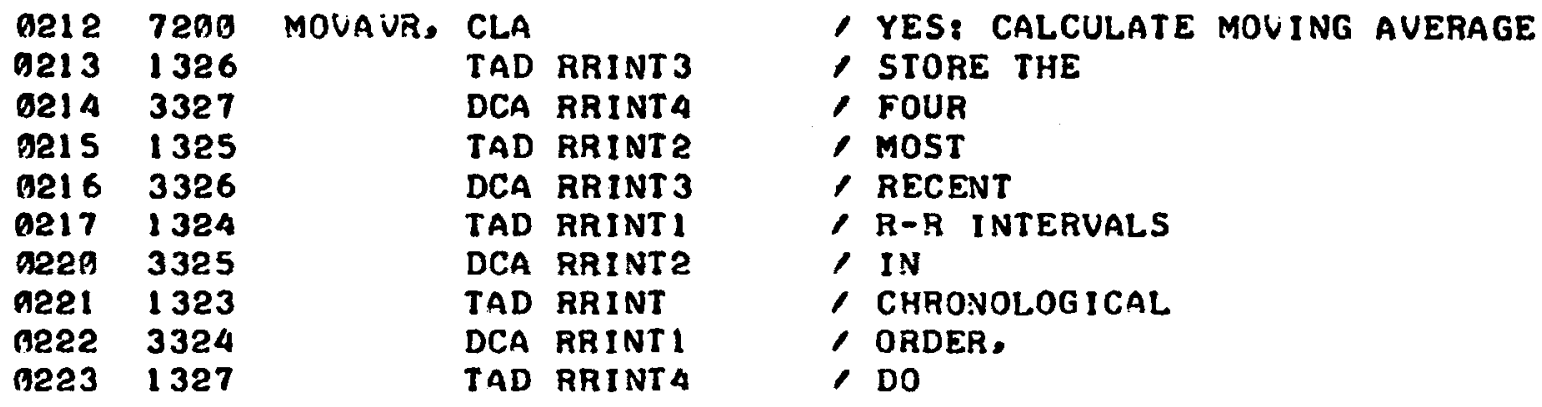




$\begin{array}{ll}9224 & 1326 \\ 0225 & 1325 \\ 9226 & 1324 \\ 0227 & 7110 \\ 9230 & 7110 \\ 9231 & 7430 \\ 9232 & 7901 \\ 0233 & 3323\end{array}$

, ROUTINE TO RESET CONTROL WORDS AND COUNTERS
TAD RRINT 3

TAD RRINTE

TAD RRINTI

CLL RAR

CLL RAR

SZL

IAC

DCA RRIVT
1 ADDITION

1 OF

, LAST FOUR INTERVALS,

1 DIVIDE SUM

1 BY 4

1 AND STORE

1 AUERAGED

, R-R-INTERVAL

$\begin{array}{ll}9234 & 7209 \\ 9235 & 1341 \\ 9236 & 3339 \\ 9237 & 1341 \\ 9249 & 3331 \\ 9241 & 1341 \\ 9242 & 3332 \\ 9243 & 1337 \\ 9244 & 3333 \\ 9245 & 1349 \\ 9246 & 3334 \\ 9247 & 1337 \\ 9259 & 3335 \\ 9251 & 1323 \\ 9252 & 7949 \\ 9253 & 3336\end{array}$

$9254 \quad 2336$

92557416

02565319

\begin{tabular}{|c|c|c|}
\hline INIT, & CLA & \\
\hline & $I \cap D$ & $\times 4.909$ \\
\hline & DCA & HORP $w \mathrm{G}$ \\
\hline & IAD & 14999 \\
\hline & DCA & HORGRP \\
\hline & TAD & K4900 \\
\hline & DCA & VRTPOS \\
\hline & TAD & MIØ \\
\hline & DCA & PWGMIA \\
\hline & TAD & M5 \\
\hline & DCA & GRPM5 \\
\hline & TAD & M1O \\
\hline & DCA & VRTMI A \\
\hline & TAD & RRINT \\
\hline & CMA & \\
\hline & DCA & COUNTR \\
\hline
\end{tabular}

\section{- Clear acCumulator}

, INITIALIZE

, CONTROL

, WORDS

, FOR

- RELAY

, REGISTERS

1 AND

, RESET

1 COUNTERS

, FOR

1 RELAY

, SELECTION

, SET UP COUNTER

I ACCORDING TO

, MILLISECONDS ELAPSED

ROUTINE TO DETERMINE NUMBER OF LOOPS
LOOP,
IS7. COUNTR
SKP
MPP LOADRG
1 COUNTER $=$ a ?
, NO: MODIFY CONIROL WORD(S)
, YES: LOAD RELAY REGISTERS

/ ROUTINE TO DETERMINE A LIGHT'S POSITION WITHIN A HORITON, TAL GROUP: ONE ROTAIION FOR EUERY MILLISECOND

$\begin{array}{ll}3257 & 7390 \\ 7269 & 1339 \\ 3261 & 7919 \\ 7262 & 3339 \\ 3263 & 2333 \\ 9264 & 5254 \\ 7265 & 1337 \\ 3266 & 3333 \\ 7267 & 1341 \\ 9279 & 3339\end{array}$

MSECA1, CLA CLL
TAD HORPWG
RAR
DCA HORPWG
ISZ PWGMIO
IMP LOOP
TAD MIG
DCA PWGMIO
TAD KAOGG
DCA HORPWG

- CLEAR AC AND LINK

, GET RELAY CONTROL WORD I

, ROTATE AC AND LINK RIOHT

- SAUE RELAY CONTROL WORD 1

19. ROTATION ?

, NO: LOOP BACK

- YES: RESTORE PIGMIO

- AS counter

/ CLEAR BIT I I AND SET BIT 3

- of RElay CONTROL WORD I

ROUTINE TO SELECT ONE OF FIVE HORIZONTAL GROUPS:

, ONE ROTATION FOR EVERY IO MILLISECONDS

MSECIG, TAD HORGRP RAR

DCA HORGRP

ISZ GRPMS

JMP LOOP
- GET RELAY CONTROL WORD 2

, ROTATE AC AND LINK RIGHT

I SAVE RELAY CONTROL WORD 2

/ 5. ROTATION ?

- NO\& LOOP BACK 


$\begin{array}{ll}0276 & 1349 \\ 0277 & 3334 \\ 3399 & 1341 \\ 0391 & 3331 \\ & \\ & \\ 9392 & 1332 \\ 9303 & 7319 \\ 9394 & 3332 \\ 9305 & 2335 \\ 9396 & 5254 \\ 0307 & 5319\end{array}$

$\begin{array}{ll}0319 & 7299 \\ 0311 & 1339 \\ 0312 & 6141 \\ 3313 & 7293 \\ 9314 & 1331 \\ 9315 & 6143 \\ 9316 & 7209 \\ 9317 & 1332 \\ 9329 & 6145 \\ 3321 & 5233\end{array}$

TAD MS

DCA GRPMS

TAD $Y 4990$

DCA HORGRP
, YES, RESTORE GRPMS

- AS COUNTER

- clear bit 10 and SET bIt 0

$f$ OF RELAY CONTROL WORD 2

- ROUTINE TO DETERMINE A LIGHT'S POSITION WITHIN THE

, VERTICAL STRING: ONE ROTATION FOR EUERY 5 A MSECS

, ROUT INE TO Close THREE RELAyS

MSEC5A, TAD VRTPOS
RAR
DCA VRTPOS
IST. VRTMIA
MMP LOOP
MMP LOADRG

, GET RELAY CONTROL WORD 3

$\checkmark$ ROTATE AC AND L.INK RIGHT

I SAVE RELAY CONTROL WORD 3

10. ROTATION ?

I NO: LOOP BACK

/ YES: OUT OF RANGE; NO VERT - LIGHT

LOADRG, CLA
TAD HORPWG
LDRI
CLA
TAD HORGRP
LDR2
CLA
TAD URTPOS
LDR3
IMP IVPUT

/ SELECT AND CLOSE

, ONE RELAY

I IN .RELAY REGISTER I

, SELECT AND Close

, ONE RELAY

I I.v RELAY REgISTER 2

, SELECT AND CLOSE

, ONE RELAY

, IN RELAY REGISTER 3

, RETURN TO WAITING LOOP

\begin{tabular}{|c|c|c|c|}
\hline C: & 3307 & ENARLE, & 33.7 \\
\hline 323 & 9999 & RAINT, & $903 a$ \\
\hline 32 & 9090 & RR INTI, & 990 \\
\hline 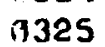 & 9930 & RR INT 2 , & 900 \\
\hline & 9096 & RRINT 3 , & 690 \\
\hline 32 & 39 & RRI & a \\
\hline 33 & an & HORPSG, & 9ดด \\
\hline 33 & ดด & HOF & 390 \\
\hline 33 & Вกถด & VRI & mogs \\
\hline 333 & 3ாดก & PWG & 9908 \\
\hline 334 & $\operatorname{man}$ & GRPMS. & agBo \\
\hline 335 & ตถดต & VRTMIO, & 3500 \\
\hline 336 & OBAB & COUNTR, & $9 \operatorname{ang}$ \\
\hline 337 & 7766 & Mis, & 776 \\
\hline 34 & 77 & M5, & 777 \\
\hline & 4900 & K4609 & $490 \pi$ \\
\hline
\end{tabular}

I CLOCK CONTROL WORD

, LAST R-R INTERVAL IN MILLISECONDS

, TEMPORARY

, STORAGE

, OF LAST

, R-R INTERVALS

- RELAY CONTROL WORD 1

I RELAY CONTROL WORD 2

- RELAY CONTROL WORD 3

- ROTATION COUNTER 1

- ROTATION COUNTER 2

- ROTATION COUNTER 3

- LOOP COUNTER

- DECIMAL - 16

, DECIMAL - 5

- oCtal 4900 (AIT $\theta=1$ )

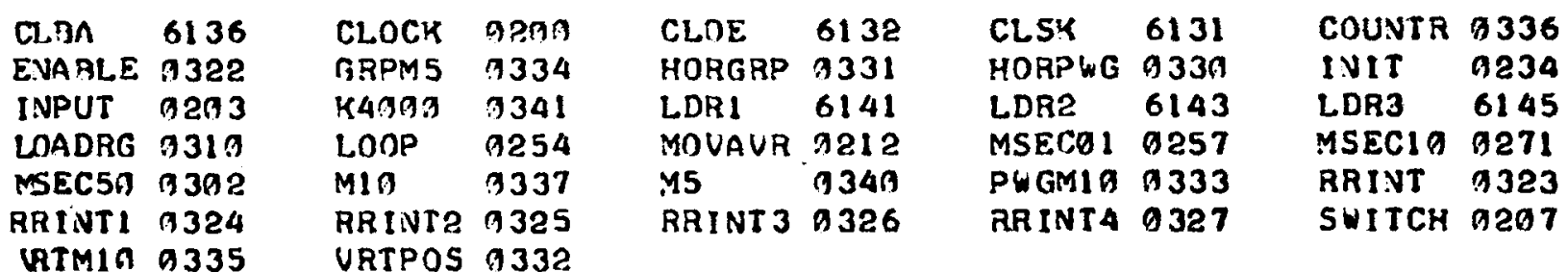

